\title{
The Role of Multiparametric Magnetic Resonance Imaging in the Diagnosis of Prostate Cancer
}

\section{Prostat Kanseri Tanısında Multiparametrik Magnetik Rezonans Görüntülemenin Yer}

\author{
Erdem Öztürk ${ }^{1}$ \\ ${ }^{1}$ Dr. Abdurrahman Yurtaslan Ankara Onkoloji Eğitim ve Araştırma Hastanesi, Ankara
}

Dergiye Ulaşma Tarihi: 25.07.2018 Dergiye Kabul Tarihi: 07.08.2018 Doi: 10.5505/aot.2018.50023

\section{ÖZET}

GÍRIŞ ve AMAÇ: Prostat kanseri erkeklerde en sık görülen kanser olup, taramasında dijital rektal muayene (DRM) ve kan prostat spesifik antijen (PSA) seviyesi ölçümü kullanılmaktadır. Yakın geçmişte prostat kanseri açısından şüpheli hastaların tanısında multiparametrik magnetik rezonans görüntüleme (MpMRI) kullanımı giderek artmıştır.

$\mathrm{Bu}$ çalışmada kliniğimizde prostat kanseri şüphesi ile MpMRI yapılan hastaların Prostat Görüntüleme Raporlama ve Bilgi Sistemi (PI-RADS) skorları transrektal ultrasonografi (TRUS) kılavuzluğunda yapılan prostat biopsisi patolojileri ile karşılaştırılmıştır.

YÖNTEM ve GEREÇLER: Kliniğimizde Ağustos 2017-Ocak 2018 tarihleri arasında PSA değeri $\geq 4 \mathrm{ng} / \mathrm{ml}$ ve/veya DRM'de şüpheli bulgular nedeniyle prostat biyopsisi planlanan 40 hasta çalışmaya dahil edildi. Tüm hastalar biyopsi öncesinde mpMRI ile değerlendirdi ve sonrasında TRUS eşliğinde kognitif biyopsi yapıldı. Olguların yaş, PSA düzeyi, DRM bulguları kaydedildi. Hastaların mpMRI'larındaki Pi-RADS skorları biyopsilerinde saptanan Gleason skorları ile karşılaştırıldı

BULGULAR: Hastaların ortalama yaşı $64 \pm 9,4$, ortalama PSA değeri 9,85 $\pm 3,87 \mathrm{ng} / \mathrm{ml}$, ortalama prostat boyutu ise $61 \pm 18$ gr idi. Yapılan histopatolojik inceleme sonucunda 40 hastanın 24 'ünde prostat kanseri saptandı. MpMRI sonrası yapılan kognitif biyosinin prostat kanseri saptamadaki duyarlılı̆̆ $\% 87.5$ iken özgüllü̈̆̆̈̈ \%68.75 olarak bulundu. Prostat kanseri şüphesi olan hastalarda MpMRI görüntüleri sonucu raporlanan Pi-RADS skorunun pozitif prediktif değeri (PPV) \%80.7 iken negatif prediktif değeri (NPV) ise \%78 olarak hesapland.

TARTIŞMA ve SONUÇ: Mevcut bilgiler ışı̆ı̆ndan prostat kanseri açısından şüpheli hastalarda MpMRI yapılması ve Pi-RADS skoru yüksek odaklardan biyopsi yapılması önerilmektedir.

Anahtar Kelimeler: Multiparametrik magnetik rezonans görüntüleme, prostat biyopisi, prostat kanseri

\section{ABSTRACT}

INTRODUCTION: Prostate cancer is the most common cancer among men population, and clinical suspicion of prostate cancer is typically based on digital rectal examination and/or the finding of elevated prostate spesific antigen (PSA). Nowadays MpMRI has an emerging role in diagnostic evaluation of prostate cancer. In this study, we aimed to evaluate the Prostate Imaging Reporting and Data System (Pi-RADS) scores with the results of transrectal ultrasound (TRUS) guided targeted cognitif prostate biopsy.

MATERIAL and METHODS: We evaluated the data of 40 patients who underwent MpMRI and TRUS cognitif biopsy due to suspicion of prostate cancer and/or $\geq 4 \mathrm{ng} / \mathrm{ml}$ PSA value and/or abnormal digital rectal examination at our clinic between August 2017 - January 2018. Patients age, PSA values and digital rectal examinations were recorded. A retrospectif review of Pi-RADS scores according to MpMRI and biopsi, Gleason scores were compared.

RESULTS: Overall, biopsies were positive in 24/40 patients. The mean age, the mean PSA value and the mean prostate volüme of patients were $64 \pm 9,4,9,85 \pm 3,87 \mathrm{ng} / \mathrm{ml}$ and $61 \pm 18 \mathrm{~g}$, respectively. Sensitivity, specificity, negative predictive value and pozitif predictive value of Pi-RADS scores according to MpMRI were $87.5 \%$, $68.75 \%, 78 \%$ and $80.7 \%$, respectively.

DISCUSSION and CONCLUSION: MpMRI may be recommended for evaluation of prostate cancer suspicious cases and prostate biopsy will be performed according to Pi-RADS scores.

Keywords: Multiparametric magnetic resonance imaging, prostate biopsy, prostate cancer 


\section{GİRIŞ}

Prostat kanseri (PK) erkeklerde görülen en sik kanserdir (1). Zaman içerisinde gelişen tanı ve tedavi yöntemlerine rağmen, günümüzde prostat kanseri, kanser ilişkili ölümün en sik sebeplerinden biridir (2).

Prostat kanseri taramasinda dijital rektal muayene (DRM) ve kan PSA seviyesi ölçümü kullanılmaktadır. Tarama sonucunda şüpheli vakalardan transrektal ultrasonografi (TRUS) eşliğinde prostat biopsisi yapılmaktadır. TRUS eşliğinde yapılan prostat biopsisinin tanısal değeri \%22 ila \%43 arasında değişmekte olup $(3,4)$, bu teknikle kanser hastalarının yaklaşık \%30'unun atlandığı bilinmektedir (5).

Son dekadda prostat kanseri açısından şüpheli hastaların tanısında multiparametrik magnetik rezonans görüntüleme (MpMRI) kullanımı giderek artmıştır. Genel olarak MpMRI çekiminde T2 ağırlıklı sekanslara ek olarak difüzyon ağırlıklı görüntüleme (DWI) ve dinamik kontrastlı seriler alınmaktadır. Avrupa Ürogenital Radyoloji Birliği (ESUR) tarafindan yeni geliştirilen Prostate Imaging and Reporting and Data System: Version 2 (PIRADS v2), şüpheli kanser olgularında lezyonu saptama, lokalize etme, karakterize etme ve risk düzeyi saptanmasını arttırmak için tasarlanmıştır (6). Bu skorlama sistemine göre hastalar MpMRI görüntülerine göre 1'den 5'e kadar puanlanmakta ve risk siniflaması yapılmaktadır.

$\mathrm{Bu}$ çalışmada kliniğimizde prostat kanseri şüphesi ile MpMRI yapılan hastaların PI-RADS skorları TRUS kılavuzluğunda yapılan prostat biopsisi patolojileri ile karşılaştırılmıştır.

\section{YÖNTEM ve GEREÇLER}

Kliniğimizde Ağustos 2017-Ocak 2018 tarihleri arasında PSA değeri $\geq 4 \mathrm{ng} / \mathrm{ml}$ ve/veya DRM'de şüpheli bulgular nedeniyle prostat biyopsisi planlanan 40 hasta çalışmaya dahil edildi. Tüm hastalardan yapılacak işlemler ile ilgili bilgi verilerek yazılı onam alındı. Tüm hastalar biyopsi öncesinde MpMRI ile değerlendirdi ve sonrasında TRUS eşliğinde kognitif biyopsi yapıldı. Tüm hastalarda sistematik 12 odakl1 biyopsi yapılırd. Olguların yaş, PSA düzeyi, DRM bulguları değerlendirildi. Histopatolojik değerlendirme sonucu PK gelen numunelerin Gleason dereceleri kaydedildi.

\section{Multiparametrik Manyetik Rezonans Görüntüleme ve Transrektal Ultrason Eşliğinde Biyopsi}

Tüm hastalar 3 Tesla MRI ile T2 ağırlıkl, dinamik kontrastlı ve difüzyon ağırlıklı görüntüler olmak zere 3 sekans kombine edilerek incelendi. Deneyimli bir radyolog tarafından Pi-RADS skorlama sistemine göre puanlama yapıldı. Takiben tüm hastalara TRUS eşliğinde sistematik 12 odaklı prostat biyopsisi yapıldı. MpMRI'de malignite açısından şüpheli odak belirlenen olgularda sistematik biyopsiye ek olarak bu şüpheli odaklardan da en az 2 adet biyopsi örneği alındı. Tüm hastalara biyopsi öncesi aynı protokole göre antibiyotik (oral siprofloksasin ve intramuskuler gentamisin) profilaksisi ve lokal anestezi (prilokain) uygulandi. Tüm biyopsiler 18G iğne kullanılarak yapıldı.

\section{İstatistiksel Analiz}

Tüm değerlendirmeler için ki-kare testi kullanıldı. İstatistiksel olarak $\mathrm{p}<0,05$ değeri anlamlı olarak kabul edildi.

\section{BULGULAR}

Hastaların ortalama yaşı $64 \pm 9,4$, ortalama PSA değeri $9,85 \pm 3,87 \mathrm{ng} / \mathrm{ml}$, ortalama prostat boyutu ise $61 \pm 18$ gr idi (Tablo 1). Çalışmaya dahil edilen 40 hastanın 3'ünün daha öncesinde negatif prostat biyopsisi olduğu öğrenilirken, 37 hastadan ilk defa prostat biyopsisi yapildı.

Tablo 1. Hastaların demografik özellikleri

\begin{tabular}{|l|c|}
\hline Yaş (yıl) & $64 \pm 9,4$ \\
\hline PSA (ng/ml) & $9,85 \pm 3,87$ \\
\hline $\begin{array}{l}\text { Prostat } \\
\text { ağırlığı (gr) }\end{array}$ & $61 \pm 18$ \\
\hline
\end{tabular}

Yapılan histopatolojik inceleme sonucunda 40 hastanın 24'ünde prostat kanseri saptandı. Prostat kanseri saptanan hastaların MpMRI'ları retrospektif incelendiğinde 24 hastanın 21 'inde Pi-RADS 3 ve üzeri skorlama yapıldı $\breve{1}$ görüldü. Geriye kalan 3 hastada MpMRI sonucunda Pi-RADS 2 olarak raporlandiğ 1 görüldü. Prostat kanseri saptanmayan 16 hastanın ise 4'ünde MpMRI sonucu Pi-RADS 3 olarak raporlanırken, 1 hastanın Pi-RADS 4 
olarak raporlandığı saptandı (Tablo 2, 3).

Tablo 2. Pi-RADS skorlarına göre hastalarda malignite saptanma oranlar1

\begin{tabular}{|l|c|c|}
\hline & Malignite (+) & Malignite (-) \\
\hline Pi-RADS 2 & $3(\% 21.43)$ & $11(\% 78.57)$ \\
\hline Pi-RADS $\geq 3$ & $21(\% 80.76)$ & $5(\% 19.24)$ \\
\hline
\end{tabular}

MpMRI sonras1 yapılan kognitif biyosinin prostat kanseri saptamadaki duyarlılığ1 \%87.5 iken özgüllügü \%68.75 olarak bulundu. Prostat kanseri şüphesi olan hastalarda MpMRI'ın pozitif prediktif değeri (PPV) \%80.7 iken negatif prediktif değeri (NPV) ise $\% 78$ olarak hesaplandi.

Tablo 3. Pi-RADS'a göre Gleason skorlarının dağılımı

\begin{tabular}{|c|c|c|c|c|c|c|c|c|}
\hline & Benign & G 3+3 & G 3+4 & G 4+3 & G 4+4 & G 4+5 & G5+4 & G5+5 \\
\hline Pi-RADS 2 & 11 & 3 & & & & & & \\
\hline Pi-RADS 3 & 4 & & 2 & 1 & & & & \\
\hline Pi-RADS 4 & 1 & 6 & & 1 & 3 & 1 & & \\
\hline Pi-RADS 5 & & & 1 & 1 & 1 & 1 & 2 & 1 \\
\hline
\end{tabular}

\section{TARTIŞMA}

Günümüzde prostat kanseri tanısı genellikle, yüksek PSA seviyeleri olan veya DRM ile şüpheli nodül saptanan hastalara yapılan TRUS eşliğinde prostat biyopisisi ile konulmaktadır. TRUS görüntülemede prostat kanseri lezyonlarının \%15'i hiperekoik, \%25'i izoekoik olarak görünmekte iken \%60'1 hipoekoik olarak izlenmektedir. Bu hipoekoik alanlardan alınan biyopsi örneklerinde kanser saptama oranı ise literatüre göre $\% 7$ ila $\% 57$ arasında değişmektetir $(7,8,9)$. TRUS eşliğinde prostat biyopsisinin invaziv ve ağrılı bir test olmasının yanında mevcut düşük tanısal değeri klinisyenleri farklı görüntüleme yöntemleri açısından arayışa yönlendirmiștir.

Yakın geçmişe kadar prostat kanserinde MRI kullanımı ekstraprostatik yayılımı saptamayı ve hastalığı evrelemeyi amaçlamaktaydı. Son y1llarda ise farklı MRI sekansları kombine edilerek prostat kanseri açısından riskli bölgeler belirlenmekte ve alınan biyopsiler bu bölgelerde yoğunlaştırılmakta ve biyopsinin tanısal değerini arttırmak hedeflenmektedir. Günümüzde prostat kanserini saptamada yüksek rezolüsyonlu T2A inceleme ile birlikte dinamik kontrastlı MRI, difüzyon ağırlıklı MRI (DWI) veya proton MRI spektroskopi gibi en az iki fonksiyonel MRI tekniği içeren MpMRI kullanılmaktadır (10). Fonksiyonel MRI teknikleri prostat hakkında metabolik bilgi, değişen hücre miktarının gösterilmesi, dokunun noninvaziv karakterizasyonu ve tümör kanlanması hakkında bilgi edinilmesini sağlar(11).

Prostat görüntüleme raporlama ve bilgi sistemi versiyon 1'in (PIRADS v1) 2012'de yayınlanmasıyla birlikte multiparametrik prostat manyetik rezonans görüntülemesine ve raporlandırılmasına ilişkin kriterler getirilmiştir. 2015 y1lında PIRADS v2 ile bu sistem geliştirilmiş ve raporlandırma basitleştirilmiştir. PIRADS v2'de MpMRI'ye küresel standardizasyon getirilmesi amaçlanmış, görüntü elde etme, yorumlama ve raporlandırmada farklılıkları azaltmak hedeflenmiş ve yaşayan bir belge olarak PIRADS v2'nin zamanla geliştirileceği vurgulanmıştır (12). $\mathrm{Bu}$ skorlama sistemi klinisyene olası şüpheli odağın yerini tariflemektedir. Lezyonlar 1 ila 5 arasinda skorlanmakta, 1-2 düşük, 3 equivokal, 4 ve 5 ise prostat kanseri açısından yüksek risk olduğunu vurgulamaktadır. Skorlama sisteminde 3 ve üzerinde skor alan hastalara biyopsi önerilmektedir.

Zhang ve ark. (13) MpMRI (difüzyon ağırlıklı görüntüler ile MR spektroskopi kombinasyonu) kılavuzluğunda yapılan TRUS biyopsi ile sistematik 12 kor TRUS biyopsi yöntemlerinin agresif PK'yi belirleme başarılarını karşılaştırmışlardır. Bu çalışmada, MpMRI kılavuzluğunda yapılan TRUS biyopsisi PK olgularının \%65'ini saptarken, sistematik biyopsinin \%36'sın1 saptadığ1 görülmüştür. Alınan biyopsi örnekleri cerrahi 
spesmen sonuçları ile uyum açısından karşılaştırıldığında; MpMRI kılavuzluğunda yapılan TRUS biyopsinin patoloji sonuçları ile daha uyumlu olduğunu (\%89,6'ya karş1 \%72,9) ve cerrahi numunelerindeki Gleason skoru arttıkça aradaki uyum farkının MpMRI kılavuzluğunda yapılan TRUS biyopsi lehine daha da arttığını bildirmişlerdir.

Osses ve ark. (14) tarafindan yapılan ve 155 hastanın dahil edildiği bir çalışmada, MpMRI'da saptanan şüpheli odaktan alınan biyopsiler ile hastalarm $\% 65$ 'inde prostat kanseri saptanmıştır. Hastalar Pi-RADS skorlama sistemine göre gruplanıp analiz edildiğinde Pi-RADS 2 olarak raporlanan hastaların hiçbirinde kanser saptanmamıştır. Pi-RADS 3 olarak raporlanan hastaların \%10'unda Pi-RADS 4 olarak raporlanan hastaların ise \%77'sinde prostat kanseri saptanmıştır. Pi-RADS 5 olarak raporlanan hastalarda ise kanser saptanma oranı \%89 olarak bulunmuştur. Prostat kanseri tanısı alan hastalar Gleason skorlarına göre incelendiğinde, genelde hastaların \%63'ünün Gleason skorunun $\geq 7$ olduğu görülürken, PiRADS 5 olan grupta bu oranın \%75 olduğu saptanmıştır. Alt grup analizlerinde Pi-RADS 2 ve 3 olan grupta $\% 91$ oranında benign patoloji elde edilirken, Pi-RADS 4 ve olan grupta patolojilerin \%81'inin malign olduğu görülmüştür. Pokony ve arkadaşları (15) tarafından yapılan bir çalışmada ise Pi-RADS 3 lezyonalrın \%15'inde, Pi-RADS 4 ve 5 lezyonların ise \%81'inde prostat kanseri saptanmıştır. Kuru ve arkadaşları (16) tarafindan yapılan bir çalışmada ise Pi-RADS 2-3 skorunun negatif prediktif değeri \%99, PiRADS 4-5'in ise pozitif prediktif değeri $\% 83$ olarak raporlanmıştır. Bizim çalışmamızdaki değerler bu kadar yüksek olmamakla birlikte klinik olarak önem arz etmektedir.

$\mathrm{Bu}$ çalışmamızda hastaların görüntülenmesinde 3 Tesla MpMRI kullanılmıştır. Günümüzde çoğu klinikte 1.5 Tesla MRI ile görüntüler elde edilmektedir. Tüm hastalara bakıldığında kanser saptama oranımız \%60 iken, Pi-RADS 3 ve üzeri grupta

\section{REFERANSLAR}

1. Jemal A, Siegel $\mathrm{R}, \mathrm{Xu} \mathrm{J}$, et al. Cancer statistics, 2010. CA Cancer J Clin 2010;60(5):277e300.

2. Gururajan M, Posadas EM, Chung LWK. Future perspectives of prostate cancer therapy. Transl Androl Urol 2012;1(1):19e32. bu oranın \%80.7 olduğu görülmektedir. $\mathrm{Bu}$ oranlar da, literatürdeki 3 Tesla MRI kullanılan çalışmalarla uyumludur. Literatürde 1.5 Tesla MRI ile yapılan çalışmalarda ise kanser saptama oranları $\% 38$ ile $\% 59$ arasinda değişmekte olup, çalışmamıza kıyasla kanser saptama oranı düşük kalmaktadır $(17,18)$. Bu veriler 1şığında 3 Tesla MRI ile değerlendirilen hastalarda kanser saptama oranının daha yüksek olduğu görülmektedir. Fakat literatürde 1,5 Tesla ile 3 Tesla MRI'ı hasta sonuçları ve patolojik veriler üzerinden karşılaştıran herhangi bir çalışma bulunmamaktadır.

Çalışmamızın bazı kısıtlılıkları bulunmaktadır. Öncelikle çalışmamız retrospektif olarak dizayn edilmiştir. Çalışmamıza alınan hastaların sayısı sınırlıdır. Hastaların Pi-RADS skorları sadece patoloji sonuçları ile karşıllaştııılmış olup radikal prostatektomi spesmenlerindeki Gleason skorları incelenmemiştir. Hastaların MpMRI görüntüleri tek bir radyolog tarafindan okunmuş olup skorlar farklı radyoloji uzmanları tarafından doğrulanmamıştır.

\section{SONUÇ}

2012 y1lında yayınlanan ve 2015 yılında güncellenen haliyle Pi-RADS skorlama sistemi tüm dünyada kabul görmüş ve MpMRI kullanımını arttırmıştır. Bu skorlama sistemi sayesinde üroloji uzmanları ile radyoloji uzmanları arasında ortak bir dil kullanılmaya başlanmıştır. Radyoloji uzmanı tarafindan tariflenen ve risk analizi yapılan lezyondan alınan biyopsiler kanser saptanma oranlarını arttırmakta ve düşük risk sınıfına alınan hastalarda gereksiz biyopsiler engellenmektir. $\mathrm{Bu}$ alanda yapılacak geniş katılımlı prospektif çalışmalarla skorlama sisteminin tanısal değeri arttırılacaktır. Sonuç olarak, prostat kanseri açısından şüpheli hastalarda biyopsi öncesi MpMRI yapılması ve Pi-RADS skoru yüksek odaklardan biyopsi alınması önerilmektedir.

\section{Çıkar Çatışması: Yok}

3. Djavan B, Ravery V, Zlotta A, et al. Prospective evaluation of prostatecancer detected on biopsies 1 , 2, 3 and 4: when should we stop? J Urol2001;166(5):1679e83.

4. Serag H, Banerjee S, Saeb-Parsy K, et al. Risk profiles of prostate cancers identified from UK primary care using national referral guidelines. Br J 
Cancer 2012;106(3):436e9.

5. Scattoni V, Zlotta A, Montironi R, et al. Extended and saturation prostatic biopsy in the diagnosis and characterisation of prostate cancer: a critical analysis of the literature. Eur Urol 2007;52(5):1309e22.

6. Prando A, Kurhanewicz J, Borges AP, et al. Prostatic biopsy directed with endorectal MR spectroscopic imaging findings in patients with elevated prostate specific antigen levels and prior negative biopsy findings: early experience 1 . Radiology 2005;236(3):903e10.

7. Sauvain JL, Palascak P, Bourscheid D, et al. Value of power doppler and 3D vascular sonography as a method for diagnosis and staging of prostate cancer. Eur Urol 2003;44:21-30.

8. Smeenge M, Mischi M, Laguna Pes MP, et al. Novel contrastenhanced ultrasound imaging in prostate cancer. World J Urol 2011;29:581-587.

9. Puech $P$, Rouvière $O$, Renard-Penna $R$, et al. Prostate cancer diagnosis: Multiparametric MRtargeted biopsy with cognitive and transrectal USMR fusion guidance versus systematic biopsyprospective multicenter study. Radiology 2013;268:461-469.

10. Barentsz JO, Richenberg J, Clements R, Choyke P, Verma S, Villeirs $G$, et al. ESUR prostate MR guidelines 2012. Eur Radiol 2012; 22: 746-57.

11. Pinto F, Totaro A, Calarco A, Sacco E, Volpe A, Racioppi $\mathrm{M}$, et al. Imaging in prostate cancer diagnosis: present role and future perspectives. Urol Int 2011; 86: 373-82.

12. PI-RADS Prostate Imaging Reporting and Data System Version 2, American College of Radiology, 2015.
13. Zhang J, Xiu J, Dong Y, et al. Magnetic resonance imaging directed biopsy improves the prediction of prostate cancer aggressiveness compared with a 12 core transrectal ultrasound guided prostate biopsy. Mol Med Rep 2014;9:1989-1997.

14. Osses DF, van Asten JJ, Kieft GJ, Tijsterman JD. Prostate cancer detection rates of magnetic resonance imaging guided prostate biopsy related to prostate imaging reporting and data system score.World J Urol. 2017 Feb;35(2):207-212.

15. Pokorny MR, de Rooij M, Duncan E et al (2014) Prospective study of diagnostic accuracy comparing prostate cancer detection by transrectal ultrasoundguided biopsy versus magnetic resonance (MR) imaging with subsequent MR-guided biopsy in men without previous prostate biopsies. Eur Urol 66:2229.

16. Kuru TH, Roethke MC, Rieker P et al (2013) Histology corespecific evaluation of the european society of urogenital radiology (ESUR) standardised scoring system of multiparametric magnetic resonance imaging (MpMRI) of the prostate. BJU Int 112:1080-1087.

17. Engehausen DG, Engelhard K, Schwab SA et al (2012) Magnetic resonance image-guided biopsies with a high detection rate of prostate cancer. sci world J 2012:971-979.

18. Roethke M, Anastasiadis AG, Lichy M et al (2012) MRI-guided prostate biopsy detects clinically significant cancer: analysis of a cohort of 100 patients after previous negative TRUS biopsy. World J Urol 30:213-218. 